
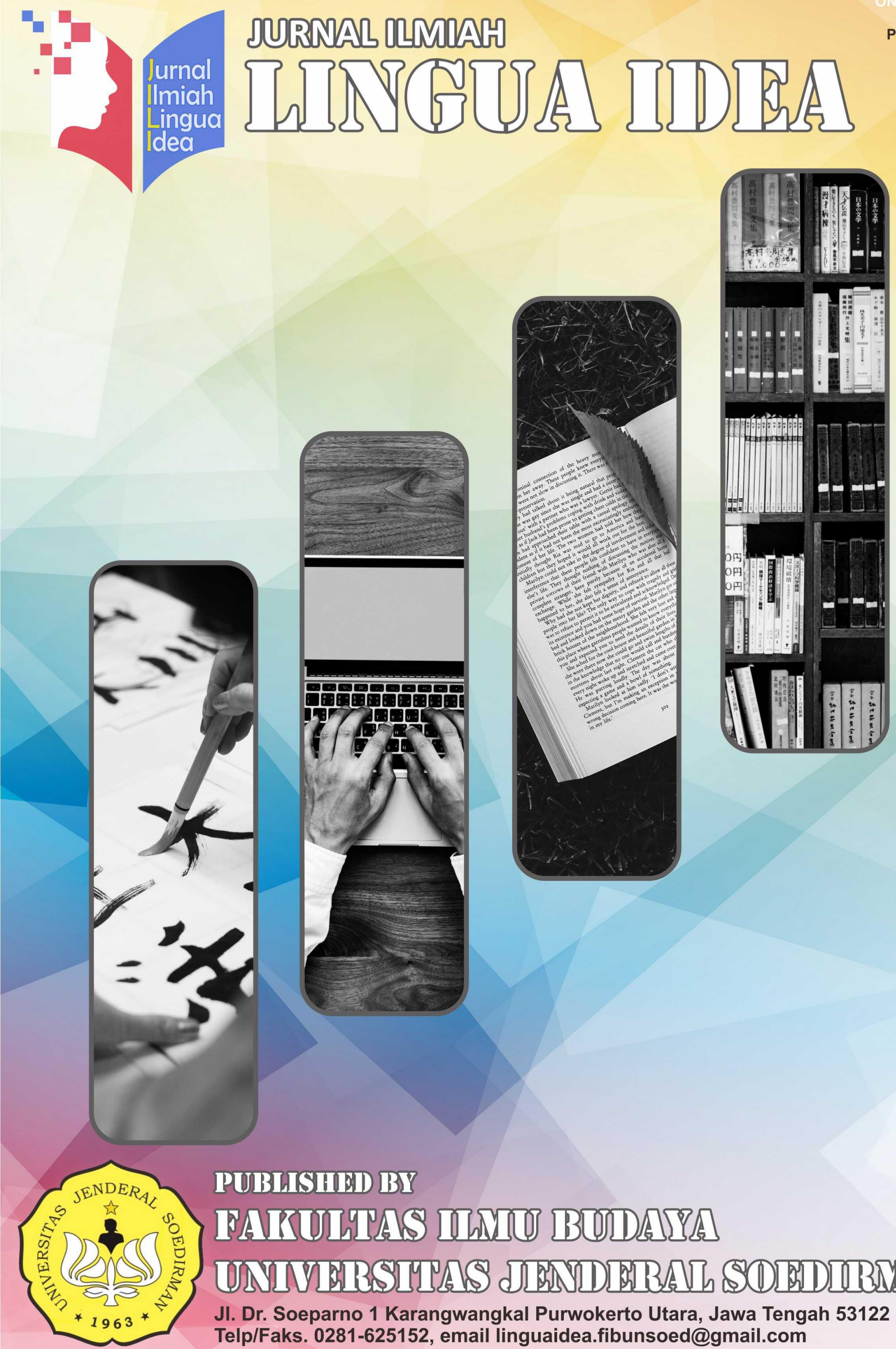

PUBTISHIMD BY

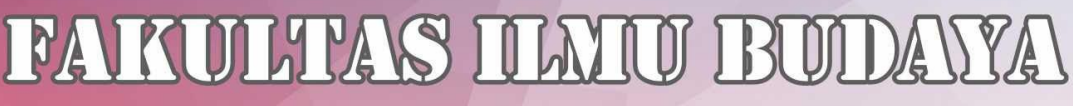

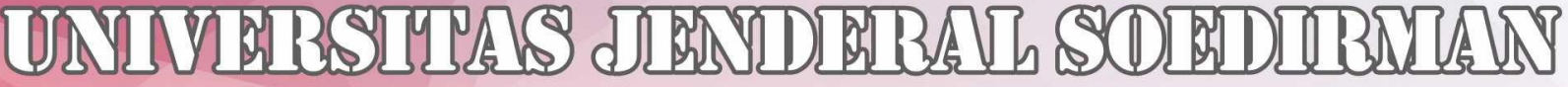
JI. Dr. Soeparno 1 Karangwangkal Purwokerto Utara, Jawa Tengah 53122 Telp/Faks. 0281-625152, email linguaidea.fibunsoed@gmail.com 
Editor in Chief

Dian Bayu Firmansyah, Fakultas Ilmu Budaya, Universitas Jenderal Soedirman, Indonesia; E-mail: dbayuf@unsoed.ac.id; (Scopus ID: 57200015393)

\section{Advisory Boards}

Aidatul Chusna, Fakultas Ilmu Budaya, Universitas Jenderal Soedirman, Indonesia

Ely Triasih Rahayu, Fakultas Ilmu Budaya, Universitas Jenderal Soedirman, Indonesia

\section{Editors}

Ambhita Dhyaningrum, Fakultas Ilmu Budaya, Universitas Jenderal Soedirman, Indonesia Eko Kurniawan, Fakultas Ilmu Budaya, Universitas Jenderal Soedirman, Indonesia Hanifa Pascarina, Fakultas Ilmu Budaya, Universitas Jenderal Soedirman, Indonesia Bagus Reza Hariyadi, Fakultas Ilmu Budaya, Universitas Jenderal Soedirman, Indonesia Vera Krisnawati, Fakultas Ilmu Budaya, Universitas Jenderal Soedirman, Indonesia

\section{Reviewers}

Chusni Hadiati, Fakultas Ilmu Budaya, Universitas Jenderal Soedirman, Indonesia

Muhamad Zainal Muttaqien, IAIN Surakarta, Indonesia

Mister Gidion Maru, Universitas Manado, Indonesia

Ekawati Marhaenny Dukut, Unika Soegijapranata, Indonesia

Nuria Haristiani, Universitas Pendidikan Indonesia, Indonesia

Hendi Pratama, Universitas Negeri Semarang, Indonesia

Lisda Nurjaleka, Universitas Negeri Semarang, Indonesia

Herniwati, Universitas Pendidikan Indonesia, Indonesia

Didik Rinan Sumekto, Universitas Widya Dharma, Indonesia

Nuriadi, Universitas Mataram, Indonesia

Agus Dwi Priyanto, Universitas Sebelas Maret, Indonesia

Herry Nur Hidayat, Universitas Andalas, Indonesia

Alo Karyati, Universitas Pakuan Bogor, Indonesia

Septi Yulisetiani, IAIN Surakarta, Indonesia

Khristianto, Universitas Mataram, Indonesia

Shintia Dwi Alika, Institut Teknologi Telkom Purwokerto, Indonesia

Umi Khomsiyatun, IAIN Purwokerto, Indonesia

Achmad Sultoni, Institut Teknologi Telkom Purwokerto, Indonesia

\section{Editorial Office:}

Gedung B Fakultas Ilmu Budaya, Universitas Jenderal Soedirman

J1. Dr. Soeparno 1, Karangwangkal, Purwokerto Utara, Jawa Tengah 53122

Email : linguaidea@unsoed.ac.id

Website $\quad:$ http://jos.unsoed.ac.id/index.php/jli/index 


\section{Focus and Scope}

Jurnal Ilmiah Lingua Idea which is published twice a year (every June and December), is a double blind peer-reviewed publication consists of research-based and review articles, fresh ideas about language, literature, cultural studies, and its teaching methodology, which have never been published before.

The journal covers all aspect relating to linguistics including:

1. Macro-linguistics;

2. Micro-linguistics;

3. Translation studies;

4. Post-colonial literature;

5. Modern literature;

6. Popular teen literature;

7. Cultural Studies;

8. Modern culture;

9. Popular culture;

10. Folk culture;

11. Educational Studies;

12. Educational Technology;

13. Teaching methodology;

14. Instructional media, etc. 
Development of High Order Thinking Skills Based Assesment Tools in Pancasila Course: 136-144 Critical Digital Citizenship Oriented

Triyani., Mustika, M., Sakman, Mantir, H. B. (Universitas Palangkaraya)

Survival Book to Help BIPA Learners Off the Hook of Culture Shock

Septiana, H., Ardiyanti, W. N., Nugroho, H. A., Mael, M. R., Ridwan, A (Universitas Negeri Surabaya)

Improving Students' Oral Communication Skills through Individual Presentation Task Burhanuddin, A. (IAIN Pekalongan)

Nyai Ontosoroh: a Female Hero and Her Resistance to Gender Injustice Waluyo, B. (Universitas Negeri Sebelas Maret)

Noun Phrases in "Imaji Terindah" Novel by Sitta Karina: A Generative Transformation Analysis

Rona Almos (Universitas Andalas Indonesia)

The Translation of Drama "Macbeth": Grammatical Transformation of Adjunct in Noun Phrase

Firda Zuldi Imamah (Universitas Diponegoro)

Banjar Language Shifting in Ecolinguistics Perspective

Saputra, I. H., Krismanti, N., Lestary. A. (STKIP PGRI BAnjarmasin)

Improving Literacy Skills of Students with Different Learning Styles Using E6tslearning

Permanasari, P., Ida Ayu Panuntun, Rizka Hayati (Universitas Pekalongan) 